\title{
ESTUDIOS
}

\section{Federico More y la formación de la tradición literaria en el Perú}

\author{
Dorian Espezúa SALMÓN \\ Universidad Nacional Mayor de San Marcos \\ solemiedu@gmail.com
}

\begin{abstract}
A la hora de la hora el Perú se divide en dos grandes bandos: traidores y patriotas.

Usted [Ventura García Calderón] no conoce nuestra literatura; usted ha copiado de todo el mundo; usted va de equivocación en equivocación; usted no sabe nada del Perú.
\end{abstract}

Federico More

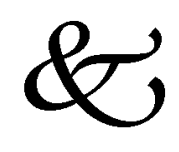

\begin{abstract}
Resumen
Este artículo aborda la faceta literaria de Federico More (1889-1955). Específicamente, trata sobre su propuesta respecto de la formación de la tradición literaria en el Perú. Como todos saben, More participó en el primer debate que, sobre literatura peruana, se realizó entre 1905 y 1928 donde también hicieron escuchar su opinión entre otros José de la Riva-Aguiero, José Gálvez, Luis Alberto Sánchez, José Carlos Mariátegui, Carlos Doig y Lora, Clemente Palma y Enrique Demetrio Tovar y Ramírez. En efecto, el ensayista puneño escribió en Buenos Aires uno de los ensayos fundadores de la crítica y los estudios literarios entre nosotros titulado: "De un ensayo acerca de las literaturas del Perú" que fue publicado en el suplemento literario del Diario de la Marina en La Habana el 23 de noviembre de 1924 y luego reproducido fragmentariamente en el diario El Norte de Trujillo en 1924 y en el número 34 de la revista
\end{abstract}


Kosko del Cuzco en 7 de marzo de 1925 (Rodríguez Rea, 2002: 99113). Una variante de este mismo ensayo con el título sintetizador de: "Sincronismo de Abelardo Gamarra, Manuel González Prada y Ricardo Palma. Los tres escritores que mejor condensan y expresan la literatura del Perú republicano" fue publicado por Francisco Igartua en su libro Andanzas de Federico More (1994: 95-117).

Palabras claves: Incaísmo, colonialismo, Federico More, Manuel González Prada, Ricardo Palma, Abelardo Gamarra.

\begin{abstract}
This article discusses the literary work of Federico More (1889-1955). Specifically, discusses his proposal for the formation of the literary tradition in Peru. As everyone knows, More participated in the first debate on Peruvian literature between 1905 and 1928 where he also did hear his opinion among others like José de la Riva-Aguiero, José Gálvez, Luis Alberto Sánchez, José Carlos Mariátegui, Charles Doig and Lora, Clemente Palma, Enrique Ramírez and Demetrio Tovar. Indeed, the puneño essayist wrote in Buenos Aires one of the founders papers of criticism and literary studies among us entitled "In an essay on the literatures of Peru" which was published in the literary supplement of The Journal of the Marine, Havana on November 23, 1924 and then reprinted in fragments in the newspaper El Norte de Trujillo in 1924 and number 34 of the magazine Kosko of Cuzco on March 7, 1925 (Rodríguez Rea, 2002: 99-113). A variant of this same essay entitled synthesizer: "Sync Abelardo Gamarra, Manuel González Prada and Ricardo Palma. The three writers who best expressed condense and literature of Republican Peru "was published by Francisco Igartua in his book Wanderings of Federico More (1994: 95-117).
\end{abstract}

Keywords: Incaísmo, colonialism, Federico More, Manuel González Prada, Ricardo Palma, Abelardo Gamarra.

Recibido: 1/12/14 Aceptado: 18/12/14 Publicado on line: 10/2/15

Federico More fue uno de los principales integrantes del grupo Colónida de fundamental importancia en la consolidación de la tradición literaria peruana. Con Colónida la literatura peruana alcanza madurez y se hace verdaderamente peruana han dicho repetidas veces los historiadores de la literatura peruana. Sin embargo, la figura de More trasciende el campo literario y se expande al plano político, social y cultural. En su peculiar estilo, por ejemplo, no está del todo claro el límite entre periodismo y literatura. Moré participó de los 
debates intelectuales con los hombres de su tiempo, con la generación que él calificó de infortunada. Fue amigo, entre otros, de Abraham Valdelomar que encarna y dirige el movimiento Colónida; del irrepetible Alberto Hidalgo con quien comparte el estilo panfletario y acusador heredado de Manuel González Prada; de Leonidas Yerovi, el escritor humorista de la costa; de José Carlos Mariátegui, el mejor de nuestros escritores políticos; de José María Eguren, la figura más sorprendente de la literatura peruana; de Luis Varela y Orbegoso (otro maestro del periodismo peruano) que lo llamó: "Una bestia con talento"; de Jorge Basadre, el más grande historiador del Perú; de Enrique López Albújar, José Gálvez Barrenechea, José Diez Canseco, etc. En lo que sigue haremos un comentario crítico sobre el ensayo mencionado en el resumen o abstract de este artículo.

Por razones de espacio no realizaré un estudio comparativo de las dos versiones indicadas que demuestran, entre otras cosas, que More reescribía sus textos como muchos miembros de su generación. Salvo se precise la fuente, todas las citas que vienen a continuación corresponden al texto publicado por Rodríguez Rea (2002). No tomaré en cuenta para nada la siniestra edición que la Universidad Nacional del Altiplano publicó con el título de Cascabel en el 2013. Dicha publicación, en realidad una selección de textos del escritor puneño hecha sin criterios académicos, no consigna los datos bibliográficos correspondientes y fue realizada por un sujeto anónimo que esconde su identidad por incompetente. Sin embargo, este sujeto desnuda su inteligencia y evidencia su ignorancia en la ridícula introducción que a la letra dice: "El amor por Puno recorre a galope limpio por toda la inteligencia de Federico More, para qué más presentaciones, aquí toda la estatura de este hombre, de esta columna que sostiene la tradición de nuestro pueblo...” (2013: 7). Es muy lamentable que la UNAP no haya contratado personal capacitado para editar la tan promocionada Biblioteca Puneña.

Creo que no se puede hablar de More si no se toma en cuenta las diferentes andanzas (Igartua: 1994) y facetas de su producción discursiva que se complementan e interrelacionan entre sí y que todavía falta recopilar y publicar. Un estudio total requiere de un conjunto de investigadores provenientes de diferentes disciplinas académicas que den cuenta de la riqueza de su producción discursiva imprescindible para conocer la historia de las mentalidades en el Perú. En efecto, en el ensayo de More acerca de las literaturas del Perú se puede rastrear muy bien su concepción de la sociedad, la cultura y la literatura peruana por lo menos en una etapa. Osmar Gonzales (2006) ha dicho de More que era rebelde y conservador y ha hecho notar su indiscutible antiaprismo del que sólo se salvó Luis Alberto Sánchez, su discutible anti-indigenismo, su firme anticomunismo y su posición antimodernizadora. A estos antis hay que agregar 
su visceral antiafronegrismo. El ensayo de More al que nos referimos no deja de tener el estilo duelista, "jocundo, cargado, grácil y ameno" (Aramayo, 2006: 24) o el estilo donde: "Los adjetivos, los epítetos, las sentencias demoledoras, las acusaciones furibundas, los calificativos inapelables poblaban sus páginas y producían una doble sensación al lector: rechazo y seducción” (Gonzales, 2006: 61). ¿Qué sostenía More en este ensayo? Que la literatura peruana era una consecuencia directa de la sociedad escindida que la producía. En efecto, en el ensayo moreano la posición que ocupa y defiende un sujeto dentro del campo intelectual depende de la posición que ocupa el mismo sujeto en el campo de lo socio-cultural.

More, de origen puneño y provinciano con un lugar importante dentro del campo intelectual limeñocentrista de la época, constata la profunda escisión o división en todos los órdenes de la vida peruana que se ejemplifica en los rencores políticos, las diferencias económicas, las tradiciones culturales, las actitudes históricas, las lenguas y las castas. More dice que en el Perú de los años 20 o se es limeño o se es incásico, es decir serrano. Es la época donde sí se puede hablar de un Perú profundo y otro Perú costeño divididos por la cordillera de los Andes. Hasta los años 20, y a esto no escapa More, la Amazonía sorprendentemente no existe en la reflexión de la intelectualidad peruana a pesar de ocupar más del $60 \%$ del territorio peruano y de ser la cuna de origen de la cultura andina. Para entender mejor la propuesta moreana, hay que ubicar su reflexión en el tránsito del periodo de la República oligárquica al periodo de crisis del estado oligárquico (García-Bedoya: 1990). Desde el punto de vista de More, desde su cronotopo y desde sus ideologemas, no se ha conseguido (todavía) fundir los dos tipos o matrices culturales que nos conforman porque ambas vertientes, aunque por caminos diferentes, desean volver al pasado. Así, anti-hispanistas y anti-incásicos son conservadores, retrógradas y carecen de perspectiva. Los proyectos son distintos y apuntan en direcciones opuestas de manera que se promueve la división. Los limeños apuntan a la colonia y los incásicos al periodo prehispánico, los andinos son rurales y los limeños urbanos. More, a pesar de ser un hombre de derecha convicto y confeso, cree que a pesar de la resistencia a la mezcla y el mestizaje, el porvenir de la sociedad peruana está justamente en el punto de encuentro de estas dos matrices culturales tal y como lo constatamos hoy casi cien años después.

Un grupo -los serranos en la terminología moreana donde también incluye a los selváticos- desciende de la raza hegemónica de rango imperial que conserva su espíritu peculiar porque, ente otras razones, no ha sido influenciados de manera sustantiva por la cultura africana y china. El ensayo de More revela todos los estereotipos y el imaginario de la época donde se nota claramente un determinismo geográfico e histórico. Así, afirma More, que los serranos 
luchan por su libertad, por librarse del coloniaje y que el clima de la sierra, "enérgicamente modelador", ha conservado "una raza casta y sobria" que usa el quechua, "lengua noble y lírica" y el castellano. En la sierra el español se ha mezclado sólo con el aborigen pero la sangre dominante siempre ha sido la aborigen. Para la época, estamos hablando de un mestizo apegado a su parte india que contrasta con el mestizo actual que niega su parte india y se apega a su lado "blanco". De este modo el serrano es predominantemente indígena en términos raciales y culturales. El resultado es el "indoespañol", el "mestizo suramericano" de quien se aguarda la nueva forma de vida y de cultura. More esta convencido de que la nueva cultura peruana tendrá una matriz predominantemente andina o serrana. Los hombres de los Andes son de un modo distinto por el rigor "telúrico" y luchan contra el centralismo limeño. Parafraseando a More, la lucha política del Cuzco contra Lima, se llama Regionalismo. Así, el Cuzco condensa la tradición andina, serrana y rural. Las ciudades de la sierra, según More, fueron abandonadas por los criollos una vez agotada la explotación de los productos naturales de la región. Esto explicaría por qué el Perú estaría lleno de "aldehuelas menesterosas y ridículas" en las que cien mestizos que siempre andan en pos de un puesto público siguen manteniendo el Coloniaje. Hablamos de una sierra poblada en su mayor porcentaje habitada por indios analfabetos y todavía regida por la trinidad embrutecedora del indio; una sierra dividida en castas sociales y con fuerte presencia autoritaria de hacendados.

En el ensayo en cuestión, un representante de la literatura serrana es Percy Gibson. En efecto, More afirma que él que es el poeta que mejor ha sentido la sierra aunque inmediatamente después diga que "no sabe de historia" y agregue que: "En cambio, prodúcenle crisis musicales de inefable subjetivismo, la emoción inmemorial y teosófica de los trigales maduros de color crepuscular o la leyenda que las brujas amargaron" (103). Sin embargo, y a pesar de su explícita inclinación por el mestizaje, no se puede ocultar el marcado sesgo racista desde un lugar de enunciación que evidencia predominantemente un proyecto "civilizador" de lo serrano que devendría en mestizaje. ¿Por qué More no toma en cuenta a un representante de la sierra que sea mestizo o indio y que escriba en lengua indígena? Es poco probable que More desconociera la tradición colonial en la que, por ejemplo, el teatro se escribía en quechua. Es también difícil demostrar que More conociera la tradición republicana de la escritura en lengua indígena. Sin embargo, por lo que se desprende del ensayo, el periodista puneño intuye que la literatura en lengua indígena en su época se circunscribe a la recopilación de la tradición oral o a la producción mestiza de literatura "popular". No conoce autores indígenas o mestizos que hayan "escrito" y publicado en lengua indígena. 
Otro grupo -el costeño-limeño en términos de More- desciende de gentes que, si bien son vástagos de conquistadores se contentaron al fin con ser colonia. Los costeños, según el intelectual puneño, añoran el coloniaje y aman la esclavitud. En la costa hubo amalgamas étnicos, el español se mezcló con el chino, con el negro y el aborigen de manera tal que esta cultura ha sufrido la influencia -More cree que la culpa la tiene el clima- del potencial voluptuoso de los negros y los chinos. Nótese aquí los prejuicios que More tiene respecto de la ontología racial y cultural de los grupos subalternos que habitan en la costa y nótese también la mayor heterogeneidad sociocultural que hay en la costa si la comparamos con la sierra. Refiriéndose a la lengua, More escribe que en la costa "apenas suenan los monosílabos de las plebes de Pekín y las guturaciones de aquellos negros que fueron esclavos" (100). Se nota también en estas palabras una degradación linguiística de los chinos y los afrodescendientes puesto que éstos no tendrían lengua sino sólo dialectos y peor aún "guturaciones". Los chinos y negros, a diferencia de los indios, no tienen lengua y menos literatura. En consecuencia, en el esquema mental de More hay una jerarquía por la cual lo serrano-andino-selvático-quechuaymarañol es superior a lo costeño colonialoccidental-hispánico que a su vez es superior a lo oriental y afroperuano. Para More, Lima condensa lo urbano y todas las taras del coloniaje y el Cuzco sintetiza lo peruano y el porvenir. Sin el ánimo de justificar a More y para no descontextualizarlo juzgándolo desde nuestra posición de hombres del siglo XXI, habría que decir que su pensamiento no escapa al paradigma de la mentalidad criolla de los años 20.

El "Incaísmo" es una alternativa frente a esta radical escisión. En efecto, el Incaismo de inicios del siglo XX se basa en el "espíritu" de los Andes influido por el "alma" hispánica. "Este Incaísmo nuestro es un poco cristiano y mucho occidental. Piensa y habla en español y se enorgullece de que España le dé -en dosis razonablemente asimilable- su temple histórico y el empuje de su vigoroso individualismo; su fiero señorío municipal y el grave curso de su pensamiento" (102). El Incaísmo cristiano y occidental que se expresa en castellano logra amalgamar una temática peruana con una expresión española mediada por la ideología del cristianismo que se opone al indigenismo nativo y no cristiano que se expresa en lengua nativa. Por otro lado, está el coloniaje del que More dice: "Quien reniega del coloniaje, no reniega sólo de la manera como lo transformaron un clima fatal, un concurso étnico deplorable y la ausencia de tradiciones indígenas. El clima de la costa peruana; el concurso étnico de la costa peruana. De la costa peruana, cuyo único pasado está en los tres siglos de servidumbre que suma la Colonia" (102). Cuatro, según la cita anterior, son las causas del colonialismo costero: el clima fatal, el mestizaje étnico deplorable en el que participan negros y "chinos", la ausencia de tradiciones indígenas 
y los tres siglos de servidumbre. No es difícil deducir que para More como para su maestro Manuel González Prada el "espíritu" o el "alma" de la cultura peruana debe buscarse en el Perú que está detrás de la cordillera de los Andes y no en el que habita la costa donde arraigó profundamente el coloniaje. En otra parte More dice:

Las regiones andinistas, el incaísmo, aún no tienen el sumo escritor que sintetice y condense, en fulminantes y lucientes páginas, las inquietudes, las modalidades y las oscilaciones del alma incaica. El sumo escritor trágico y eglógico, lleno de abismos y fragancias, de rumor apacible de regatos y estrépito tenaz de cataratas. El sumo artista en el que las montañas y las llanuras, la nieve y el rayo, la vicuña célebre y el quinual dorado surjan, a manera de cromos, de acordes, de relieves, con la gracia y la firmeza que el arte pone sobre la realidad heterogénea. El sumo escritor que funda alma, paisaje, historia, naturaleza, costumbrismo, tradiciones y anécdotas dentro de un estilo andino y al influjo bruñidor y armonizante de una sensibilidad intransferible y sin embargo universal (More 2002 [1924]: 106).

Para el escritor puneño la literatura peruana está en formación y todavía no ha alcanzado la madurez suficiente como para producir un escritor que sintetice o condense, en un estilo andino, las tradiciones escindidas representadas por la costa y la sierra. Cabe recordar aquí que ya César Vallejo había publicado Los heraldos negros (1918-1919) y Trilce (1922) amalgamando bien ambas tradiciones. En el habitus de More como en el de su generación la tradición oral no llega a tener el rango de literatura. Todo parece indicar que More no conocía el trabajo de Adolfo Vienrich que 1905, el mismo año que José de la Riva Agüiero publica Carácter de la literatura del Perú independiente, publica en Tarma Azucenas quechuas. Vienrich, que inicia el lento proceso de incorporación de la tradición oral al sistema literario nacional, también publicó Aurora Pacha Huaray, el primer periódico bilingüe quechua castellano, y Apólogos quechuas en 1906. O More no consideró escritores a los cronistas indios y mestizos como Felipe Guamán Poma de Ayala o a El Inca Garcilaso de la Vega a quien llama indirectamente fantaseador o no estuvo informado, por lo menos hasta la fecha de publicación de este ensayo, sobre la interesante producción que se gestaba por ejemplo en Puno, su tierra natal, por el grupo Orkopata. Por razones de orden cronológico More no estuvo al tanto de la producción del poeta cuzqueño Andrés Alencastre Gutiérrez (Kilku Waraka) cuya producción poética se da a partir de 1955. Obviamente, More no conoció la brillante producción de José María Arguedas o Gamaliel Churata que sintetizan muy bien el proyecto de una literatura verdaderamente nacional.

La literatura es para More un reflejo y una consecuencia de la sociedad postcolonial, premoderna, fragmentada, desarticulada que nos condujo a la 
derrota con Chile. Así como la sociedad está dividida, la literatura también está dividida básicamente entre serranos y limeños; así como en la época de More la nación estaba en formación, la literatura peruana también estaba en formación. En buena cuenta, ni Palma, ni González Prada, ni El Tunante reúnen los requisitos que More busca en un escritor representativo de lo que llama el Perú integral. La literatura serrana es rural o se ocupa de temas rurales y de pobladores rurales, la literatura limeña es urbana y se preocupa de temas urbanos y de pobladores urbanos. More, sin hacerlo explícito, trabaja con dicotomías como costeño/serrano, urbano/rural, civilización/barbarie, propio/foráneo, indio/ español, Manco Cápac/Francisco Pizarro, centralismo/regionalismo, castellano/ quechua, pasado/futuro, Cuzco/Lima o incaísmo/colonialismo que obviamente contribuye a superar. La división entre limeños y serranos se mantiene hasta hoy en que se sigue dando el improductivo debate entre escritores andinos y criollos en un contexto donde se han borrado las fronteras de las dicotomías planteadas por More. ¿Esto probaría que tanto nuestra nación como nuestra literatura todavía están en proceso de formación? Recordemos a More cuando dice:

Para quienes actúan bajo la influencia de Lima, todo tiene idiosincrasia iberafricana; todo es romántico y sensual. Para quienes actuamos bajo la influencia del Cuzco, la parte más bella y honda de la vida se realiza en las montañas y en los valles y en todo hay subjetividad indescifrada y sentido dramático. El limeño es colorista; el peruano, musical. Para los herederos del Coloniaje, el amor es un lance. Para los retoños de la raza caída, el amor es un coro transmisor de las voces del destino (More 2002 [1924]: 102-103).

No se puede dejar de comentar la sutil diferencia que More hace entre lo limeño que en este caso es el coloniaje y lo peruano (serrano) donde More se incluye y que estaría influenciado por el Cuzco, símbolo de la cultura serrana. En el esquema de More, no obstante, lo limeño y lo serrano son criticables en diversos grados por sus componentes étnicos, por sus idiosincrasias, por sus culturas, por sus lenguas, por sus escritores que no vinculan ambas perspectivas con las que se debe formar el Perú integral. Pero, en el estilo comparativo de More, la balanza se inclina, como es predecible, por lo serrano antes que por lo costeño. En otra parte de su interesante ensayo sobre literatura More afirma:

En la sierra aman la leyenda. En la costa, la historia. La historia como ciencia; es decir, el adefesio cronológico. Allá imaginan o intuyen. Acá se documentan. En el fondo de todo escritor colonial hay un apologista. En el de los escritores incaicos, un panfletario. Cuando se rebela, el del Coloniaje chicolea. Mientras elogia, el del imperio se rebela. De ahí que en la sierra se tienda al humorismo y en la costa no sea posible salir de la picardía: esto revela, tanto como lentitud 
enfermiza para la reacción, horror congénito a la Trascendencia (More 2002 [1924]: 103).

Ambas tradiciones literarias, la costeña y la serrana, son nuevamente criticadas en la cita anterior. La serrana (que antes había sido calificada como de subjetividad indescifrable, con sentido dramático y musical), donde los escritores son panfletarios, rebeldes y humoristas, por preferir la leyenda, la imaginación y la intuición; la costeña (descrita como romántica, sensual, con idiosincrasia iberafricana y colorista), donde los escritores son apologistas, elogiosos y pícaros, por preferir la historia (el adefesio cronológico) y la documentación. Es a todas luces notorio que las opiniones de More están basadas en prejuicios, generalizaciones y estereotipos que contribuye a solidificar. Luego, refiriéndose a lo religioso, More agrega: "Para los herederos del alma quechua, Dios es todo o Todo es dios. Los costeños más bien son idólatras y no ven la religión sino un elemento decorativo de orden suntuario escultural, arquitectónico o literario. Ama la imagen de un santo, una catedral rítmica, la pompa de las liturgias, el esplendor verbal de las homilías. Son, pues, urbanos" (103). Estas palabras constituyen sin duda una dura crítica a la religiosidad tanto de la sierra donde hay un pensamiento de orden teocéntrico que impediría el progreso como para la costa heredera de una sociedad colonial con doble moral y apegada a la pompa del ritual que también impediría la integración.

Entonces tenemos que para More la literatura costeña, en clara alusión a Ricardo Palma y a lo que representa, se caracteriza por tener una idiosincrasia iberafricana (Recordemos que para More la voluptuosidad africana es despreciable y perjudicial), por ser romántica, sensual y colorista, por estar basada en la historia como adefesio cronológico, porque se inclina por la documentación antes que por la imaginación, por su apología del coloniaje, por su picardía hipócrita que revela lentitud enfermiza para la reacción y por la cucufatería religiosa y superficial. En cambio, la literatura serrana a la que More llama peruana y por la cual evidentemente siente predilección se caracteriza por la subjetividad indescifrada (me suena a desconocimiento de la cosmovisión andina o india), por el sentido dramático que connota lucha, sufrimiento y acto heroico, por la musicalidad asociada al lenguaje poético (discurso) antes que a la historia, por la leyenda, la intuición y la imaginación que nos remiten a la (re)creación de mundos posibles, por ser panfletaria en tanto se enfrenta al centralismo y sus representantes, por su humorismo antes que por su melancolía y por su sincera religiosidad. Por otro lado, en términos idiomáticos, More sostiene que el limeño es más academicista y reaccionario por cuanto está pegado a las normas, en cambio el serrano es más creativo puesto que explota el potencial expresivo del idioma. More dice: "Los escritores serranos actúan 
con estilos propios, a las veces deficientes, nexando su sensación y su ideación con la sierra misma; con la tierra múltiple en sonidos y colores, siempre para el arte" (104). En efecto y aunque parezca paradójico, More reconoce en los escritores serranos una mayor originalidad que los escritores limeños y un mayor compromiso por vincular la literatura y la realidad. More forma parte de aquellos intelectuales que reclaman la construcción de una forma de expresión propia que recoja, en una lengua híbrida, el contacto linguístico que se da entre el castellano y las lenguas andinas y selváticas.

El que mejor ejemplifica la literatura limeña y colonial es Ricardo Palma de quien More dice que es un divertido narrador de chascarrillos fichados y anaquelazos que "Escribe con vistas a la Academia de la Lengua y, para contar los devaneos y discreteos de las marquesitas de pelo ensortijado y labios prominentes, quiere usar el castellano del siglo de oro" (103). Así, lo criticable en Palma es, para More, las historias recopiladas y fichadas sacadas del pasado colonial, el uso del lenguaje arcaico propio del Siglo de Oro y los temas de negros y mulatos que representan lo limeño, costeño y colonial. Esto guarda concordancia con el anti-afronegrismo y anti-colonialismo moreano. Recalco la idea de que para More, hacia los años 20, el serrano es más conservador -en el sentido de resistencia cultural- que el limeño y por lo tanto menos aculturado o transculturado. El limeño es más proclive a la alineación porque su resistencia a la invasión cultural es mucho más débil. En cambio el serrano, sin ser fundamentalista, resiste más los procesos de homogeneización cultural porque defiende su cultura ancestral. Mientras que en el serrano la inteligencia y sensibilidad universal "crean vastos socavones sicológicos", en el limeño no logran repercusión alguna: "Así se comprende que en cuestiones idiomáticas los limeños sean academicistas y en política reaccionarios. No hay problema ideológico o sentimental que en Lima haya producido ecos. $\mathrm{Ni}$ el modernismo en literatura ni el marxismo en política; ni el símbolo en música ni el dinamismo expresionista en pintura han inquietado a los hijos de la ciudad sedante. La Voluptuosidad es tumba de la Inquietud" (104). La cita es por lo menos curiosa puesto que More exagera la dicotomía con un afán provocativo y con su estilo confrontacional dado que conocía perfectamente a Mariáteguí que en 1928 funda el Partido Socialista del Perú y conocía también los aportes de José Santos Chocano, de Clemente Palma, de Abraham Valdelomar o del propio Ventura García Calderón.

En otro momento, cuando More introduce el tema del primer precursor, dice: "La literatura sólo es traducción de un estado político y social. El mayor defecto de la literatura limeña es que no traduce sino un estado sexual: fuera de aventuras galantes, chismorreos palatinos y divagaciones histórico-heráldicas, no conoce nada. La nación peruana no le debe nada" (104). Aquí nuevamente 
More es maniqueo puesto que, según esta lógica instigadora e insultante, la literatura limeña no aporta con casi nada en la consolidación de una literatura nacional. De las citas anteriores se colige que para More la literatura peruana, si es que quiere ser verdaderamente peruana, debe dejar de ser colonial (limeña) y buscar su originalidad en la vertiente serrana. En otras palabras, y siguiendo el pensamiento de González Prada, la identidad de nuestra literatura hay que buscarla detrás de la cordillera de los Andes y no en la franja costera del Perú. Invirtiendo el fraseo atribuida a Valdelomar, diríamos que el Perú es la sierra, la sierra es lo indígena y lo indígena es lo nacional.

Para More, el "primer precursor" de la literatura nacional es Manuel González Prada de quien dice que tuvo una actitud de apóstol humanitarista y positivo que nos dio una lección objetiva de pedagogo culto. En efecto, el ensayista puneño escribe: "Cuando nace en Lima un gran escritor, Manuel González Prada, si bien no puede sustraerse a ciertas deficiencias de su ciudad natal, únese, desde el primer instante de su carrera, a los ideales serranos" (104). Según More, el acierto de González Prada consiste en adherirse e identificarse con lo indo-mestizo serrano y en dejar constancia de los vicios limeños que son vicios coloniales. En efecto, González Prada fue el crítico más severo que tuvo la sociedad postcolonial que Palma recordaba con nostalgia. Pero más adelante dice: "Aunque se alejó un poco del urbanismo limeño, no supo acercarse al espíritu agreste y montañés de los antiguos campos imperiales" (105). Entonces, estamos frente a una identificación y adhesión superficial que sólo ve la sierra desde una posición distante, pero que no se mezcla ni se compromete. El reconocimiento discursivo de la sierra como el espacio donde hay que buscar lo nacional no necesariamente va parejo con la inclusión práctica de lo indígena en la vida nacional. La orientación política de González Prada no deja de ser una visión indigenista desde varios puntos de vista.

Si bien More resalta el amor de González Prada por lo que él llama el "Perú integral" que apenas entrevió y rescata ciertas virtudes como sus reclamos de que el Perú se confedere, que el problema rural sea resuelto, que la administración sea saneada, que la vida política se nacionalice; aunque lo haga a la europea, a lo erudito - como dice More- y "teniendo a la vista los tratados jurídicos y sociales que nacieron al cabo de una cultura secular y superior" (105); también lo critica fuertemente cuando sostiene que recae en el limeñismo, cuando lo califica de "anacoreta laico", virtuoso, frío y severo o cuando dice de él que es un "Trágico vicioso de la virtud". Compara a González Prada con las "mujeres hermosas que envejecen custodiando su doncellez" (105) cuando afirma que vivió cuidándose de no pecar o cuando señala que nunca actuó porque tenía miedo de que la acción lo pervirtiese y tenía miedo del peligro. En efecto, More reprocha a González Prada su falta de concordancia y coherencia entre el decir 
y el hacer de modo que le reclama su falta de acción y un liderazgo efímero e inconsecuente. En otra parte califica a González Prada de "Poeta empeñado en actuar de caudillo desde la torre de marfil, atalaya olímpica que no sirve de palenque ni de tribuna” (105). Además, remarca las limitaciones de González Prada cuando sostiene que "Fue sólo un conductor de caravanas. Tan indeciso que las dejó en mitad del desierto" (105-106) o cuando lo muestra incapaz de meditar sobre el antagonismo principal de la sociedad peruana. Al fin y al cabo en González Prada como en More existen contradicciones insalvables propias de intelectuales inmersos en las circunstancias y mentalidades inseparables a la época que a cada uno le correspondió vivir.

Es muy sorprendente que después de más de 400 años de mestizaje étnico y cultural, sólo a inicios del siglo XX se reclame el mestizaje también en la tradición literaria peruana a pesar de la existencia de escritores precursores en tal tarea. En el ilustrativo ensayo que comentamos, More apuesta por una literatura mestiza cuyo "primer ejemplar" es producto de las regiones andinas que produjeron un hombre como Abelardo Gamarra a quien More considera de "acelerada inteligencia" y como un hombre "amador instintivo de la justicia". Pero Gamarra -apunta More- "No fue, por desgracia [...] el artista redondo y facetado, limpio y fulgente, el cabal hombre de letras que se necesita" (106). Es, por lo tanto, sólo otro precursor en la tarea de vincular la tradición costeña con la tradición serrana. Los méritos y deméritos literarios de Gamarra son al mismo tiempo: "El amor a un regionalismo idiomático a ratos parecido a modo dialectal, y el haber intentado la fusión de las tendencias linguiísticas de la sierra y la costa -maridaje imposible, unión contranatura-" (106). Para More el bilinguiismo impidió que Gamarra hablara con "armoniosa dignidad": "Y sin embargo, el lenguaje de Gamarra encierra los matices e inflexiones de un estilo completo. Posee la gracia sensual y truhanesca de las tierras costeñas, y la mordiente acidez y el grave ritmo de la voz serrana" (107). En lo formal, el mestizaje peruano se evidencia en la lengua que es el primer componente cultural con el que y con el que se entra en contacto cultural. ¿Por qué More considera "maridaje imposible" o "unión contranatura" la fusión de las tendencias linguísticas de la sierra y la costa? ¿Por qué el bilingüismo es un impedimento? Parece ser que en la concepción de More el quechua y el castellano son como el agua y el aceite y que el resultado del contacto linguístico entre estas dos lenguas es "raro" para su gusto estético. La lengua ideal para More es el castellano andino, es decir, el castellano como base con algunas influencias de las lenguas andinas. Hago notar aquí que la construcción de una lengua híbrida o misturada requirió de un largo proceso de maduración que llegó a su cumbre con José María Arguedas y Gamaliel Churata en prosa y con Alejandro Peralta y César Vallejo en Poesía. Veamos en la siguiente 
cita cómo en el pensamiento de More la vida y la obra de un escritor están vinculados de manera indisoluble:

Gamarra conoció las virtudes y vicios de su tierra; fue dueño de sentido político, de orientación social y de perspicacia psicológica. Tuvo del artista la facultad de excitarse; del maestro, la aptitud de comunicar su entusiasmo; del hombre de lucha y práctico, el don de abrir los ojos dentro de la realidad y ver la infraestructura de los hechos como los buzos la flora submarina. Supo aprehender espacio y tiempo, captarlos como conjuntos históricos, relacionarlos y reducirlos a fórmulas. Comprendió las sugestiones oscuras de la geografía y la herencia, de la educación y el instinto. Su estilo es donairoso y ágil, incisivo y vívido. Hombre equilibrado y férvido, sereno y tumultuoso, vivió una existencia fragosa y abigarrada sin que el vivirla le desposeyera de candor, de ingenuidad infantil, de esa pureza de alma en que, desde los místicos y los iluminados, fúndase la televisión y que constituye la esencia del hondo poder intuitivo de los líricos nórdicos (More 2002 [1924]: 107).

Antes de cerrar su discutible ensayo que, no obstante, muestra un discurso no consciente del que el autor no se da cuenta, More vuelve a Gamarra y nuevamente lo presenta como el modelo de mestizaje aunque resaltando que es un mestizo en el que no hubo sangre africana. El mestizaje para More margina los componentes culturales provenientes del África y del Asia que, más bien, son perjudiciales para la nación y cultura peruana en el esquema mental de More que, a su vez, es un reflejo del modo de pensar de la intelectualidad peruana de inicios del siglo XX.

Abelardo Gamarra mantuvo en su espíritu los matices esenciales del ancestro asiático y se dejó influir generosamente por el Cristianismo y por la cultura occidental. Tampoco desdeñó lo que el Coloniaje atesoraba de culto por la elegancia, de afición a las bellas palabras, a la emoción madrigalesca del amor y al sentido pecaminoso de la voluptuosidad. Quizá el mayor mérito de Gamarra consiste en haber hospedado, dentro de su alma activa y absolutamente peruana, panquechua, las corrientes de la cultura europea y el curso africano de la vida colonial. Gamarra así, resulta el escritor mestizo por excelencia. Un mestizo que no olvida nunca el respeto debido a la justicia y a los homenajes que merece todo aquello en que se expresa algo ideal. Un mestizo en el cual no hubo sangre africana y en el que la sangre española fue la necesaria para dosificar el raudal quechua. Nacido en tierra que los incas conocieron, en tierra andina y bajo el encanto rural de las tradiciones de la raza (More 2002 [1924]: 110-111).

¿Por qué Gamarra es el primer ejemplar de la literatura nacional? ¿Por qué merece un monumento en el Cuzco? More habla de un "secreto racial" por el cual: "Gamarra atisbó que el Perú sin incas no es nada" (107). Para More, 
en el tiempo histórico de toda nuestra larga Historia, el coloniaje, que no es españolismo puro, es un episodio relativamente breve que no debe afectar sustantivamente el origen "puro" de nuestra nacionalidad predominantemente andina. El coloniaje no debe afectar nuestro tronco cultural como decía José Martí o nuestra matriz cultural predominantemente indígena en términos de Serge Gruzinski. Esta visión idealizada contrasta con la realidad dado que, por el contrario, se constata, en el propio lenguaje y texto de More, la enorme influencia que la cultura occidental ha tenido en la formación del Perú integral.

Gamarra no ignoró que el coloniaje no es una civilización, ni puede ser base de una cultura. Apenas si es un episodio histórico que significa para el Perú lo que podría significar para Francia la invasión inglesa de la guerra de los cien años. Quienes sostienen que el Perú se funda en el Coloniaje, reniegan del origen puro e ilustre de la nacionalidad y se empeñan en convertir en título la bastardía. Lo que se llama propiamente el Coloniaje, es el conjunto de hechos luctuosos, galantes y frívolos que se desarrollaron entre 1620 y 1820 y cuya inercia es la república hasta hoy. Quienes creen que el Coloniaje representa el máximo dominio del españolismo puro, están en un error (More 2002 [1924]: 107-108).

Más adelante, More reduce el coloniaje a la costa y a Lima cuando afirma que: "El Coloniaje en el Perú es un hecho limeño" (108). Después dirá, con un tono racista que se opone al mestizaje de todas las sangres, que el Coloniaje, cuya prolongación es la República, es: "Conservadurismo nórdico, sensualidad irrefrenable, desdén por la inteligencia, matriarcado encubierto. Eso no es español. Tampoco es quechua. Eso es lo que crean, bajo un clima incubador de sátiros y ninfas, hombres en cuyas venas se confunden las sangres del chino, del negro, del indio y del español" (108). Es sintomático que en el esquema dicotómico de More, que segrega lo "chino" o lo negro y todo tipo de mestizaje, o se es heredero de la tradición española o se es heredero de la cultura quechua. Pero -aunque More diga que esto no está probado del todonuestro "secreto racial" tampoco sería del todo original puesto que el mismo More, siguiendo algunos estudios antropológicos, sostiene que más bien las poblaciones suramericanas tienen un origen asiático, un poco tibetano que se manifiesta en las similitudes culturales y en las formas de pensar, sentir y expresarse del hombre de la sierra.

En términos literarios la conclusión moreana es predecible a pesar de los elogios y las críticas: "Gamarra es uno de los más felices y encendidos precursores del panperuanismo integral. Su pensamiento y emoción gravitarán sobre todas las conciencias. Y mientras de González Prada quedará sólo el ritmo cadencioso y de Ricardo Palma la risilla chocarrera, de Gamarra quedará el sentimiento vital. El Perú empezará a conocerse a través de Gamarra” (113). Para corroborar esta conclusión veamos la siguiente cita: 
González Prada es el europeísmo puro. Ricardo Palma el africanismo colonial: en los esguinces de su léxico el lector adivina el ceceo; Abelardo Gamarra es el iniciador de la literatura de los mestizos; de la literatura que un día será de los accidentalizados e hispanizados herederos de los quechuas. Sin pedantería, sin citas abundantes, sin recursos académicos, sin ostentaciones de políglota, Abelardo Gamarra dijo, en el lenguaje del pueblo los dolores y los ensueños del pueblo (More 2002 [1924]: 112).

Del ensayo de More se desprende que en La formación de la tradición literaria en el Perú (Cornejo Polar, 1989) coexisten tres vertientes. La primera, hegemónica, hunde sus raíces en la tradición colonial (limeña) a la que según More: "La nación peruana no le debe nada". Recordemos que para el escritor puneño el coloniaje es un hecho exclusivamente limeño. La segunda vertiente, residual, la constituye la tradición serrana en la que, a diferencia de la primera, se encuentra la fuente de la cultura peruana que resistió al coloniaje. Pero aquí no se puede incluir a La otra literatura peruana (Bendezú, 1986). Desde la perspectiva de More la tercera vertiente, la emergente, es la literatura mestiza que sintetiza las dos grandes matrices de la cultura peruana: la hispana y la andina. Pero el mestizaje de More es exclusivo y excluyente por cuando considera perjudicial tanto la voluptuosidad heredada de África como la sangre de los chinos. Para More el mestizo "ideal" es el indoespañol y el indeseado es aquel en cuyas venas se confunden mezcladas todas las sangres. Sin embargo, y paradójicamente, More apunta a la formación de un Perú integral o de un panperuanismo integral en el que se encuentren las diversas razas, culturas, tradiciones y actitudes históricas. Un apunte final: las mujeres no existen para More.

\section{Referencias bibliográficas}

ARAMAYO, Omar (2006) "Sólo una máscara para los varios rostros de Federico More". En Osmar Gonzales (2006): Federico More. Un maestro del periodismo peruano. Lima, Universidad Alas Peruanas; pp. 21-37.

BENDEZÚ, Edmundo (1986) La otra literatura peruana. México D. F.: Fondo de Cultura Económica.

CORNEJO POLAR, Antonio (1989) La formación de la tradición literaria en el Perú. Lima: Centro de Estudios y Publicaciones.

GARCÍA-BEDOYA MAGUIÑA, Carlos (1990) Para una periodización de la literatura peruana. Lima: Latinoamericana editores.

GONZALES, Osmar (2006) Federico More. Un maestro del periodismo peruano. Lima: Universidad Alas Peruanas.

IGARTUA, Francisco (compilador)(1994) Andanzas de Federico More. Lima: Metrocolor S.A. MORE, Federico (2002) [1924] "De un ensayo acerca de las literaturas del Perú" en Miguel Ángel Rodríguez Rea (2002). La literatura peruana en debate: 1905-1928. Lima: Universidad Ricardo Palma; pp. 99-113. 
MORE, Federico (2013) Cascabel. Puno: Universidad Nacional del Altiplano.

RODRÍGUEZ REA, Miguel Ángel (2002) La literatura peruana en debate: 1905-1928. Lima: Universidad Ricardo Palma. 